\title{
As estratégias de descentralização orçamentária com vistas ao desenvolvimento e suas incongruências com a prática no espaço regional
}

\section{Budget descentralization strategies to the development and incongruences with the practice in regional space}

José Elmar Feger - doutor em Desenvolvimento Regional pela UNISC-Santa Cruz do Sul, professor e pesquisador do Setor de Educação Profissional e Tecnológica da Universidade Federal do Paraná (UFPR).E-mail elmar@ufpr.br; elmar.josefeger@gmail.com

Ilton Nunes dos Santos - mestre em Gestão e Auditoria Ambiental pela Universidad de León, Espanha (2010), professor da Universidade do Oeste de Santa Catarina (UNOESC), gerente da Agência de Desenvolvimento Regional da Associação dos Municípios do Nordeste Riograndense (AMUNOR) e monitor do Ministério da Integração Nacional nos cursos de Gestão Estratégica de Desenvolvimento Local e Regional. E-mail: Ilton.santos@unoesc.edu.br

Augusto Fischer - doutor em Administração pela Universidade de São Paulo (USP); pesquisador e professor no mestrado profissional em Administração, na Universidade do Oeste de Santa Catarina (UNOESC).E-mail augusto.fischer@unoesc.edu.br

\section{Resumo}

O tema do estudo se insere na discussão sobre as políticas públicas voltadas ao desenvolvimento regional. O foco da pesquisa foi o Programa Consulta Popular e sua aplicação pelo Conselho Regional de Desenvolvimento da Região Nordeste do Estado do Rio Grande do Sul, no período compreendido entre 2006 e 2009. A investigação se enquadra na estratégia de estudo de caso único. Quanto ao método, caracteriza-se como de cunho quali-quantitativo. Quantitativo, visto que analisou o montante de recursos aplicados em quatro edições do programa objeto de estudo. Qualitativo, ao buscar na visão das lideranças locais, por meio da análise de seus discursos, a razão do investimento. Concluiu-se que os agentes locais concentram os investimentos na área de saúde e segurança, deixando de contemplar outras que também são importantes para o desenvolvimento. Como causas desse fato identificam-se a inexistência de planejamento regional e a articulação de agentes locais para angariar recursos para seus projetos.

\section{Palavras-chave}

Projetos Sociais em Espaços Regionais. Política Pública. Desenvolvimento Regional. Orçamento Descentralizado. Participação Popular.

\begin{abstract}
The subject of this study belongs in the discussion about public policies focused on the regional development. The focus of the research was the Popular Consulting Program and its application by the Regional Council of Development of the northeastern region from Rio Grande do Sul State, between 2006 and 2009. The research uses the strategy of single case study. As for the method it is characterized as qualitative and quantitative nature. Quantitative in order to analyze the amount of resources applied in four editions of the program of this study. Qualitative in order to understand the local leadership vision through analysis of their speeches the reason of the investment. It was concluded that local actors concentrate investments in the area of health and safety, failing to consider other that also are important for development. Like causes of this fact, there is identified the lack of regional planning and coordination of local actors to raise funds for their projects.
\end{abstract}

\section{Keywords}

Social Projects in Regional Spaces. Public Policy. Regional Development. Decentralized Budget. Popular Participation. 


\section{INTRODUÇÃO}

Ao tratar da temática do desenvolvimento regional, na atualidade, se assume que as decisões são tomadas com mais acerto por quem está mais próximo dos problemas. Assim, nas suas estratégias de gestão, os governos procuram atuar de forma descentralizada, buscando a participação da sociedade via entidades representativas locais, tanto na identificação de prioridades, como, muitas vezes, na decisão de aplicação de determinada parcela do seu orçamento.

O almejado objetivo de propiciar melhores condições de vida para as populações regionais tem se pautado em ações subsidiadas por recursos endógenos, dentre eles, a aplicação dos orçamentos dos próprios municípios, como também no incentivo à inversão por parte da iniciativa privada. Em virtude da amplitude dos problemas, todavia, há necessidade de obter recursos exógenos, muitas vezes junto ao governo estadual e/ou federal, via apresentação de projetos para captação de recursos voluntários desses entes públicos. No caso do Rio Grande do Sul, uma ação de descentralização e fonte de recursos exógenos para as regiões consiste na Consulta Popular, um programa do Governo Estadual, por meio do qual um percentual do orçamento é destinado à região, e ela, sob a articulação de seu COREDE, determina de que forma ele será investido.

O tema abordado no estudo que originou este artigo corresponde ao referido programa, objetivando compreender a sua aplicação no território gaúcho. Diante da dificuldade em se obter dados com a devida profundidade em todos os Conselhos de Desenvolvimento, delimita-se espacialmente o estudo a um deles, o Conselho Regional de Desenvolvimento da Região Nordeste, composto por 19 municípios, doravante identificado, neste trabalho, como COREDE NORDESTE. No que tange à delimitação temporal, buscou-se acompanhar a aplicação do programa em quatro períodos, abrangendo os anos de 2006, 2007, 2008 e 2009.

O principal objetivo do programa Consulta Popular é o combate às desigualdades regionais via investimentos em necessidades de cada localidade. Nesse sentido, a orientação do estudo se pautou na questão: qual a destinação dada pela comunidade domiciliada no COREDE NORDESTE aos recursos obtidos via programa Consulta Popular no período compreendido entre os anos 2006 e 2009 ?

Assim, tem-se como objetivo geral do estudo verificar a destinação dos recursos do programa Consulta Popular na região objeto de estudo entre os anos 2006 e 2009. Especificamente, pretendeu-se identificar as áreas que receberam a maior fatia dos recursos no período; analisar as dimensões do desenvolvimento sustentável que receberam inversões de recursos do referido programa; e 
identificar quais as razões, na visão das lideranças da região, que levaram as populações a optarem pela destinação dos recursos para as áreas priorizadas.

O artigo encontra-se estruturado em cinco seções, sendo que a primeira é a sua introdução. Na sequência, apresenta-se o referencial teórico e, em seguida, discute-se a metodologia empregada, segue-se com a apresentação e discussão dos dados e as considerações finais.

\section{POLÍTICAS PÚBLICAS E REGIONALIZAÇÃO DO DESENVOL- VIMENTO}

\subsection{Acepções teóricas sobre desenvolvimento e políticas de descentralização da gestão}

Ao longo da história emergiram inúmeros conceitos de região e espaço, uma vez que não se consegue isolá-los devido ao elevado número de disciplinas envolvidas na análise regional (HADDAD, 1989). Lencioni (1999) aborda o tema numa perspectiva dialética demonstrando que a região é parte de um todo maior [global] em constante movimento. Daí a grande dificuldade metodológica do recorte regional único e geometricamente pré-estabelecido. Ao tratar desse assunto, Santos (1997) se referiu à região como o lugar de realização de determinadas atividades que, a cada momento histórico, admite novas formasconteúdo, materializando, assim, subespaços de um espaço nacional. Paiva (2005) entende a região não como uma entidade física, mas como uma construção social. Define-a como o resultado de um processo de regionalização. Esse processo é função dos objetivos daqueles que o colocam em curso, logo, "um mesmo território pode e deve ser objeto das mais distintas regionalizações".

$\mathrm{Na}$ concepção atual se aceita que a promoção do desenvolvimento ocorre com maior fertilidade quando abrange limites que superam os municipais, portanto, regionais. Ao se propor a estimular o desenvolvimento de uma região, o impulso inicial conduz ao aspecto econômico, entendendo que elaborar estratégias que tornem tal espaço competitivo economicamente, frente ao mundo globalizado, capaz de produzir e comercializar produtos de alta tecnologia e valor agregado é o caminho mais profícuo. Todavia, sob este ângulo, os agentes limitam a promoção do desenvolvimento a questões de política econômica e tributária (MARTINELLI; JOYAL, 2004).

Para evitar um estreitamento excessivo da visão dos planejadores, ampliase a discussão, introduzindo outros capitais como o humano e o social. O Capital 
Humano se refere à capacidade de as pessoas ampliarem sua capacidade de mobilização, buscando desenvolver atitudes e adquirirem conhecimentos úteis e necessários que permitam a busca pelo desenvolvimento da comunidade. Ele tem um papel importante como instrumento de mudança social, por esse motivo, pode-se dizer que o capital humano representa a capacidade do homem ser o construtor do próprio futuro (SEN, 2000). Já o Capital Social é definido como o conjunto das características da organização social, que engloba as redes de relações entre indivíduos, suas normas de comportamento, laços de confiança e obrigações mútuas. O capital social, quando existente em uma região, torna possível a tomada de ações colaborativas que resultem no benefício de toda a comunidade (PASSADOR, 2003).

Nesse contexto, uma abordagem mais recente alude que o desenvolvimento de uma região implica em elaborar estratégias que contemplem a satisfação das necessidades da geração atual, sem comprometer a capacidade das gerações futuras de satisfazerem as suas próprias necessidades, lançando os preceitos do desenvolvimento sustentável. Diante desse entendimento, passa-se a pensar na ideia de desenvolvimento local, ou seja, na regionalização das políticas sociais, na qual a função do governo não é mais a de resolver os problemas da população, mas estimular e incentivar as comunidades a se mobilizarem para que elas desenvolvam suas potencialidades e vocações e, a partir daí, resolvam os seus problemas. A participação é considerada um instrumento fundamental no sentido de promover a articulação entre os atores sociais, com o fortalecimento da coesão da comunidade e com a melhoria da qualidade das decisões, tornando mais fácil atingir objetivos comuns (SOUZA, 1999).

Assim, as políticas públicas têm origem em necessidades manifestadas pelos diversos atores sociais e se destinam a encontrar soluções conciliatórias para resolver demandas de assuntos públicos incluídos na agenda do governo. No conceito tradicional, as políticas públicas correspondem ao programa de apoio de uma autoridade pública ou ao resultado da atividade de uma autoridade investida de poder público e de legitimidade governamental, dando ao Estado papel central na resolução dos problemas coletivos (PARADA, 2002, p. 16). Para superar esse modelo de pensamento, surge um novo conceito de gestão reconsiderando as estratégias tradicionalmente adotadas na formulação de políticas públicas. As abordagens regionais passaram a ser gradativamente substituídas por iniciativas de abrangência sub-regional ou local, cuja problemática tende a ser mais homogênea (BANDEIRA, 2000, p. 31). Os defensores destes preceitos argumentam que as análises locais permitem diagnósticos mais precisos da situação e das potencialidades de uma área; a corresponsabilidade entre o Estado 
e a sociedade por meio da criação de espaços de participação na construção do público, utilizando instrumentos democráticos que possibilitam o exercício da cidadania ativa. Assim, a concepção atual de política pública permite melhorar os serviços públicos, o acesso à informação da administração pública, ampliar a participação cidadã e avaliar de forma mais adequada os resultados.

\subsection{Processo de regionalização no Rio Grande do Sul}

Diante dos novos preceitos que orientam a gestão pública, o estado do Rio Grande do Sul organiza-se em Conselhos Regionais de Desenvolvimento, a fim de facilitar o envolvimento das comunidades. Os COREDEs - Conselhos Regionais de Desenvolvimento -, criados oficialmente pela Lei 10.283, de 17 de outubro de 1994, são instâncias de planejamento regional que têm por objetivo discutir alternativas para o desenvolvimento das regiões do Estado. Atualmente, no Rio Grande do Sul, existem 28 COREDEs, os quais buscam ser um fórum de discussão e decisão relativas a políticas e ações voltadas ao desenvolvimento, articulando em nível local e setorial estratégias próprias e específicas para as regiões do Estado (ATLAS SOCIOECONÔMICO ..., 2006).

O Conselho Regional de Desenvolvimento do Nordeste Rio-Grandense, foco da presente investigação, foi instituído oficialmente em 5 de fevereiro de 1996, e atualmente é composto por 19 municípios. Dentre as suas atribuições regimentais encontram-se: promover a participação de todos os segmentos da sociedade regional, no diagnóstico de suas necessidades e potencialidade, para formulação e implementação das políticas de desenvolvimento integrado; elaborar e manter atualizado o plano estratégico de desenvolvimento de sua área de abrangência; manter espaço permanente de participação democrática, resgatando a cidadania, através da valorização da ação política; constituir-se em instância de regionalização do orçamento do Estado; orientar e acompanhar, de forma sistemática, o desempenho das ações dos governos estadual e federal em sua região de abrangência.

Em virtude do processo de regionalização e dos objetivos assumidos pelos conselhos de desenvolvimento regional, cabe ao COREDE NORDESTE articular, na sua área de abrangência, os programas do governo estadual. O programa do Governo do Estado do Rio Grande do Sul denominado Consulta Popular, instituído pela Lei $n^{\circ} 11.179$, de 25 de junho de 1998, estipula “[...] a consulta direta à população quanto à destinação de parcela do Orçamento do Estado do Rio Grande do Sul voltada a investimentos de interesse regional”. Esse processo ocorre todos os anos, quando parte do orçamento estadual é designado 
a programas escolhidos por meio de votação pela população de cada região. Os critérios são definidos por Decreto Estadual e as regras instituídas pelas próprias Assembleias de cada COREDE.

\section{METODOLOGIA}

O tema abordado na investigação foi a aplicação de recursos públicos, com vistas a induzir o desenvolvimento regional, no caso, o Programa Consulta Popular, o qual faz parte das estratégias do governo do estado do Rio Grande do Sul, e visa descentralizar a aplicação de parte dos recursos do seu orçamento anual.

Definido o tema do estudo, delimitou-se a sua abrangência espacial, no caso, a área pertencente ao COREDE NORDESTE, uma das 28 regiões em que o estado do Rio Grande do Sul encontra-se dividido visando à promoção do desenvolvimento, visto que toda pesquisa deve contemplar determinado espaço, conforme ensina GIL (2009). No tocante à delimitação temporal, outro aspecto a ser esclarecido pelo investigador, conforme o referido autor, o estudo se concentra em quatro edições do programa pauta da pesquisa, correspondendo às ocorridas entre os anos de 2006 e 2009. A investigação se enquadra na tipologia de pesquisa estudo de caso, visto que o interesse dos pesquisadores foi analisar a aplicação dos recursos do Programa Consulta Popular na região de abrangência do COREDE (GIL, 2009).

A opção pelo método de pesquisa a ser adotado deve corresponder ao que possibilita atender aos seus objetivos (GODOY, 1995). Nesse caso, pretendeuse abordar o tema por duas perspectivas, sendo que a primeira consistiu na descrição da situação e na análise da interação e do comportamento dos agentes no território, nesse caso, o método qualitativo se apresentou como o mais adequado (ALVEZ-MAZZOTTI; GEWANDSZNAJOER, 2001). A segunda consistiu em quantificar a distribuição dos recursos ao longo dos anos e verificar a sua aplicação em setores ou áreas de interesse do desenvolvimento, fazendo com que o método quantitativo se mostrasse o mais adequado (GODOY, 1995). No que concerne ao levantamento e tratamento dos dados, portanto, a presente pesquisa classifica-se como de abordagem quali-quantitativa.

No tocante à origem dos dados, esses foram de fontes primárias e secundárias. Em virtude dos objetivos do estudo, tornou-se necessário analisar os processos de distribuição dos recursos nos quatro períodos, portanto, a busca de informações em documentos. Nesse caso, trata-se de pesquisa documental e, por conseguinte, implicou na utilização de dados secundários (GIL, 2009). A

Novos Cadernos NAEA • v. 17 n. 1 • p. 9-24 • jun. 2014 
coleta desses dados ocorreu nas dependências do Conselho objeto de análise, no período de maio a dezembro de 2009, utilizando-se de documentos e materiais da diretoria que estão à disposição da população para consulta.

Para compreender as razões da decisão das comunidades por investir nos setores e projetos escolhidos, foi necessário realizar uma pesquisa de campo, valendo-se, portanto, de dados primários, visto que foram colhidos junto à população e não estavam previamente disponíveis (GIL, 2009). A coleta desses dados ocorreu por meio do envio de questionários aos 32 (trinta e dois) conselheiros do COREDE estudado, no mês de novembro de 2009, com prazo para devolução até o dia 18 de dezembro de 2009. Dos 32 formulários distribuídos, retornaram treze cuja análise subsidiou esta pesquisa, tendo como respondentes dois prefeitos, sete funcionários públicos, dois professores universitários, um vereador e um advogado. Para manter o sigilo quanto aos respondentes, na análise dos dados obtidos faz-se referência aos conselheiros nominando-os com a letra "C" seguida de um número que varia de 1 a 13.

Os dados quantitativos foram organizados em tabelas e quadros, de forma a permitir a análise da proporção dos investimentos e o direcionamento dado aos recursos. No tocante aos dados qualitativos, analisam-se as falas dos respondentes, consistindo na análise do seu discurso.

\section{DISCUSSÕES SOBRE A CONSULTA POPULAR NO COREDE NORDESTE}

Para uma melhor compreensão dos dados aqui tratados elaborou-se a Tabela 1, que traz os valores investidos na região nos anos de 2006, 2007, 2008 e 2009 pelo Programa Consulta Popular e sua respectiva percentagem no ano e período do estudo.

A Consulta Popular do ano de 2006 foi executada num período em que o Governo do Estado destinava grandes recursos para as regiões. Por não haver naquele ano a exigência de investir em programas estruturantes que alavancassem esta região, os municípios ficaram livres para escolher quais as áreas que deveriam ser contempladas com recursos. Assim, nota-se uma dispersão de valores em diversas linhas. Tendo naquele ano o valor de $\mathrm{R} \$ 2.251 .040,48$ a ser empregado na região, verifica-se que 11 áreas foram priorizadas para receber investimentos, sendo que, a maior parte foi para saneamento com 28,40\%, seguida pela área da agricultura infraestrutura com 17,99\% e em terceiro lugar, com 13,33\%, encontra-se a área da saúde. 


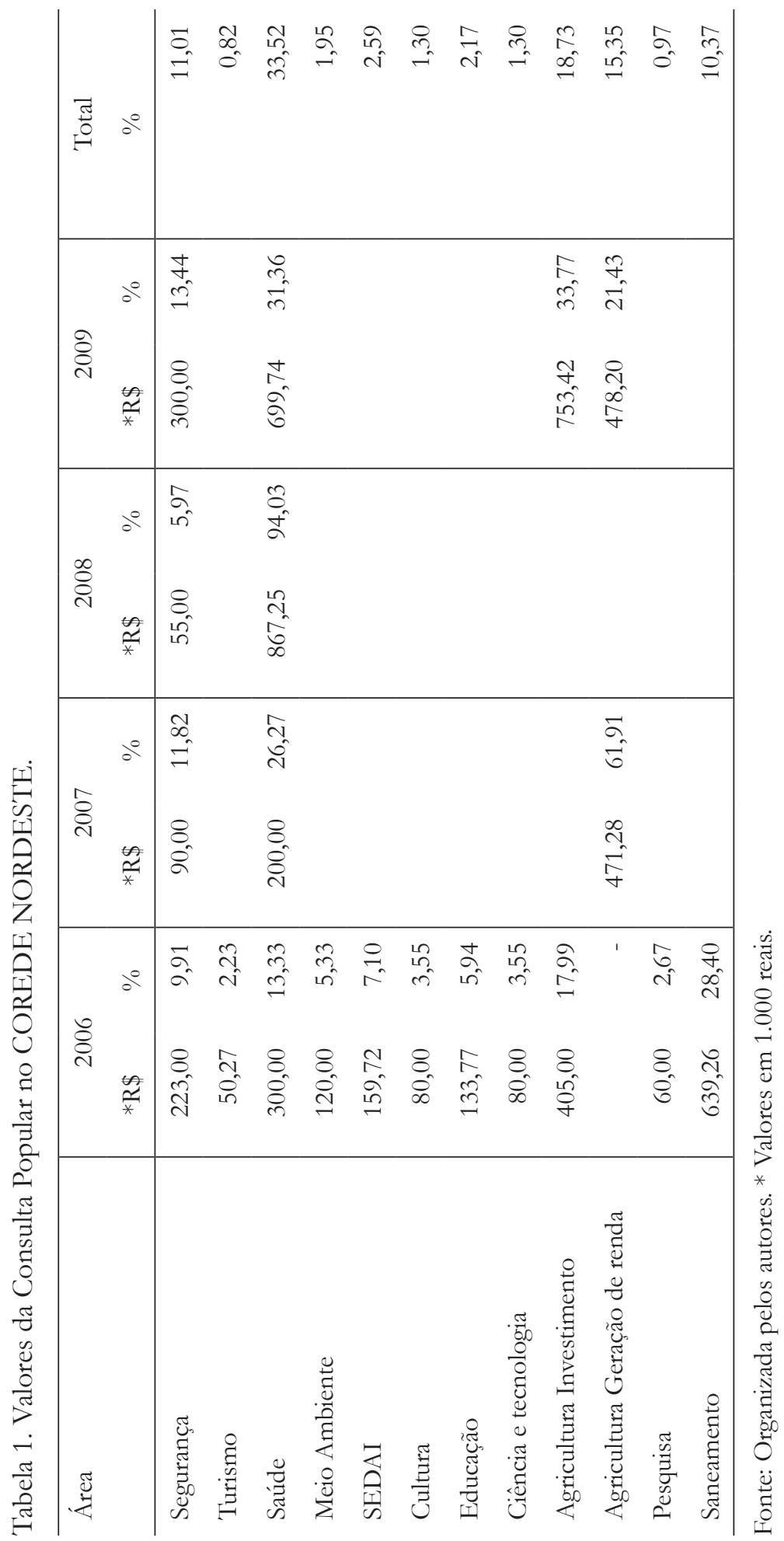

Novos Cadernos NAEA • v. 17 n. $1 \bullet$ p. 9-24 • jun. 2014 
A partir da Consulta Popular de 2007, o estado passa a adotar o sistema de financiamento a três projetos estruturantes regionais. Naquele ano, por deliberação do conselho, buscou-se eleger projetos que pudessem aumentar a geração de renda na região, optando-se por investir em um projeto ligado à agricultura e/ ou à pecuária. Assim, a maior parte dos recursos daquele ano $(\mathrm{R} \$ 761.283,32)$ financiou programas municipais voltados à fruticultura e à bovinocultura leiteira. Nesta edição do programa, em primeiro lugar contemplou-se a agropecuária com 61,91\%, em segundo, com 26,27\%, a saúde e, em terceiro, as áreas da justiça e segurança com $11,82 \%$ dos recursos destinados para o ano.

$\mathrm{Na}$ Consulta Popular de 2008, a região decidiu investir a maior parte do recurso previsto para o ano, $\mathrm{R} \$ 922.259,24$, na área da saúde. Do montante repassado, 94,03\% foram destinados a esta área e 5,97 \% para a área da segurança.

Com a Consulta Popular do ano de 2009, inicia-se uma nova sistemática. Buscando ampliar o envolvimento da comunidade, o Governo implanta bônus para regiões que mais se dedicassem, aumentando para quatro as demandas estruturantes a receberem recursos. Pela análise dos dados desse ano, observase que foram eleitas, como prioridades, para aplicação dos R \$ 1.822.000,00: a conservação de estradas de interior com 33,77\%, a área da saúde com 31,36\%, um projeto regional de geração de renda voltado para famílias de agricultores com um montante de $21,43 \%$, e a área da segurança com um projeto voltado à aquisição de material para Brigada Militar recebendo 13,44\% do valor daquele ano.

Analisando a última coluna da Tabela 1, verifica-se que nos quatro anos da Consulta Popular estudados, a região do COREDE NORDESTE investiu 33,52\% dos recursos na área da saúde, seguida pela área da agricultura investimentos (conservação de estradas, máquinas e outros) com 18,73\%. Em terceiro lugar, aparece a área da agricultura geração de renda com 15,35\%, seguida pela de segurança com $11,01 \%$ e de saneamento com 10,37\% dos recursos. No outro extremo, encontram-se as áreas de turismo, pesquisa, ciência e tecnologia, cultura e meio ambiente, que não chegaram a atingir o montante de $2 \%$ dos recursos destinados pelo programa nesse período.

Para ampliar a compreensão do tema, buscaram-se informações junto ao site do Tribunal de Contas do Estado do Rio Grande do Sul sobre a aplicação pelos municípios de recursos orçamentários próprios nas áreas da saúde, educação e agricultura. Esse levantamento teve como objetivo verificar os valores destinados a projetos pelos cofres públicos municipais sem a interferência do programa estadual em questão, visto que são determinados pela legislação brasileira. $\mathrm{Na}$ área da saúde, os municípios aplicaram, juntos, nos três anos pesquisados, o percentual 
de $18,88 \%$ de todo o recurso orçamentário, ficando acima do percentual previsto pela Emenda Constitucional 29, que prevê a aplicação do percentual mínimo de 15\% do produto da arrecadação de impostos nessa área.

Em educação, juntos, os municípios desta região alcançaram um percentual de 24,69\%, muito próximo do percentual exigido pela Constituição Federal, cujo art. 212 dispõe que a União aplicará, anualmente, nunca menos de dezoito, e os Estados, o Distrito Federal e os Municípios vinte e cinco por cento, no mínimo, da receita resultante de impostos, compreendida a proveniente de transferências, na manutenção e desenvolvimento do ensino.

No referido levantamento observou-se que há uma média de valores aplicados na área da agricultura semelhante nos 3 anos, ou seja: 4,53\% no ano de 2006, 4,50\% no ano de 2007 e 4,61\% no ano de 2008. Porém é possível verificar uma grande disparidade entre municípios. A título de exemplo, tomamse os municípios de Paim Filho e Capão Bonito do Sul. Esses dois municípios, conforme dados do PIB (produto interno bruto), apresentam índices da produção setorial da agricultura correspondes a $60,47 \%$ para o primeiro e $77,88 \%$ para o segundo município, determinando assim que sua economia é basicamente agropecuária. Ao verificar os dados de aplicação do orçamento próprio para o ano de 2006, observa-se que o primeiro, com um montante total de $\mathrm{R} \$ 5.997 .717,49$, aplicou 11,83\% em agricultura, enquanto o segundo, com um montante de $\mathrm{R} \$$ 5.327.140,25, aplicou somente $0,66 \%$ na mesma área. Essa mesma situação se repete nos anos de 2007 e 2008. Em linhas gerais, os outros municípios do COREDE NORDESTE seguem na mesma tendência, ou seja, suas economias giram em torno das atividades agropecuárias, sendo estas as maiores geradoras de renda ao setor público, porém, boa parte dos municípios não destina proporções significativas em seus orçamentos para as mesmas.

Ao consultar anotações de trabalhos elaborados pelo Governo do Estado do Rio Grande do Sul denominado de Rumos 2015, e pela Assembleia Legislativa do mesmo Estado, sob o título de Sociedade Convergente, bem como de entidades privadas chamado de Agenda 2020, todos com o foco no desenvolvimento do Estado gaúcho, nota-se que a mola propulsora da região do COREDE NORDESTE é a agropecuária, com lavouras de grãos, produção de leite, criação de animais de pequeno, médio e grande porte, atividades que despontam como geradoras de riqueza e renda para este território. Esses estudos também apontam carência de investimentos públicos nestas áreas que atualmente ordenam a economia da maioria dos municípios da região estudada. Por ser esta região basicamente ligada às atividades agropecuárias, fica o questionamento Novos Cadernos NAEA • v. 17 n. $1 \cdot$ p. 9-24 • jun. 2014 
se os percentuais aplicados pelos municípios são suficientes para promover o desenvolvimento da região.

Para verificar as razões da concentração dos investimentos nas mesmas áreas determinadas constitucionalmente, efetuou-se uma pesquisa de campo com os conselheiros do COREDE NORDESTE. Os respondentes foram questionados quanto aos objetivos do programa em estudo, a fim de verificar se a sua visão coadunava com os seus propósitos. Para "C1", o objetivo desse programa é "a melhor divisão dos recursos e uma maior participação da população nas decisões que envolvem o município"; o entrevistado "C4" coloca que "direcionar a destinação dos recursos de acordo com as demandas regionais e, indiretamente, comprometer a comunidade quanto à aplicação dos mesmos, como conquista, levando a responsabilizar-se e suscitando cuidado". Para a maioria dos conselheiros entrevistados, o objetivo do programa Consulta Popular é uma maneira da população regional opinar em quais áreas o Governo do Estado deve investir a parte do orçamento definido. Das 13 respostas, dez estão em acordo com o objetivo legal do programa, que é repassar a cada região do Estado um percentual do orçamento para que através dos votos de seus eleitores, este recurso financie projetos com potencialidade para desenvolver este território, indicando que $80 \%$ dos respondentes entendem os objetivos do programa como é pretendido pelo Estado. Todavia, três conselheiros respondem diferentemente: o "C2" coloca que o objetivo do programa é "enrolar a população com um volume muito baixo de recursos e com morosidade eterna para serem liberados"; o entrevistado "C9" coloca que o objetivo é "proporcionar recursos do Governo do Estado aos municípios. O objetivo está desfocado, não podemos mais usar este dinheiro para Polícia Civil, Militar, Escolas Estaduais, etc.”; "C11" assim se refere à questão: "ainda tenho dúvidas - o real interesse da Consulta se politiqueiro ou realmente participativo - até porque o montante repassado é muito pequeno".

Também se pretendeu na pesquisa verificar o entendimento do respondente quanto ao conceito de desenvolvimento sustentável. Grande parte das respostas coaduna com a do entrevistado "C13", o qual alega que "é o desenvolvimento que busca atender as necessidades da sociedade de forma racional (econômica, social e ambientalmente) para que as futuras gerações ainda possam usufruir dos recursos naturais e sociais. Portanto, é um desenvolvimento pensado para a melhoria da qualidade de vida da população atual e que visa garantir uma vida saudável para o futuro, o que requer constante debate e avaliação sobre os danos causados no meio ambiente e sobre a disponibilidade dos recursos não renováveis". Todavia, essa visão não é unânime. O entrevistado "C1", 
por exemplo, coloca que: "é onde o município se autossustenta e consegue fazer uma aplicação melhor dos seus recursos repassados a ele"; já para "C5", desenvolvimento sustentável "seria a sustentabilidade própria da comunidade, não ficando tão dependente das outras esferas de governo". O entrevistado "C6" responde assim: "quando os recursos são suficientes para atender as demandas existentes". Para o entrevistado "C12", desenvolvimento sustentável "é quando o município/região cresce uniforme, tanto na área econômica, social e ambiental”. Diante dos argumentos destes últimos percebe-se que compartilham de uma concepção do desenvolvimento endógeno.

Visando saber em quais ações os conselheiros respondentes teriam votado nas últimas edições, apresentou-se um rol de áreas propostas nos anos analisados, solicitando-se que o respondente assinalasse até quatro opções, conforme lembrasse em qual votou. As áreas apresentadas foram: saúde serviço; saúde equipamentos; agricultura infraestrutura; agricultura geração de renda; educação acervo bibliográfico; educação equipamentos; habitação UBS (Unidades Básicas de Saúde); habitação redes de água; justiça e desenvolvimento social; meio ambiente; turismo e FUNDERGS (Fundação do Esporte e Lazer do Rio Grande do Sul). Dos 13 questionários, foram apresentados 10 votos para "saúde serviço"; 07 votos para "justiça e segurança"; 07 votos para "agricultura geração de renda"; 06 votos para "meio ambiente"; 05 para "agricultura"; 04 para "agricultura infraestrutura"; 02 votos para "saúde equipamentos"; 01 voto para "habitação redes de água" e 01 voto para "turismo".

Analisando as respostas, pode-se verificar que a demanda que obteve maior número de votos (saúde serviço) é uma das que mais recebeu recursos do programa. A segunda mais votada pelos conselheiros consultados, "justiça e segurança", basicamente em todos os anos recebeu recursos. A terceira mais votada, "agricultura geração de renda", recebeu recursos em dois dos quatro anos analisados. A quarta com maior votação foi "meio ambiente", podendo-se inferir que para os conselheiros entrevistados é uma área de preocupação, porém para a comunidade, segundo o levantamento das demandas eleitas nas quatro edições estudadas, esta não é priorizada.

Como grande parte dos recursos do programa foi aplicada nas áreas de saúde e segurança, cujos investimentos já são garantidos constitucionalmente, solicitou-se que o respondente explicasse as razões que o levaram a escolhê-las, caso tivesse votado em uma delas. A grande maioria dos entrevistados votou nestas áreas e alegou que seu voto é justificado "pela grande necessidade de recursos nestas áreas", "por ser prioridade em meu município", "tendo em vista ser as áreas que requerem um nível maior de recursos", "ainda carecemos de mais

Novos Cadernos NAEA • v. 17 n. $1 \cdot$ p. 9-24 • jun. 2014 
investimentos em áreas sociais". Pelas respostas dos entrevistados, entende-se que um dos motivos que levam a população regional a apoiar tais áreas consiste na grande necessidade de recursos para as áreas em questão.

Alertando-se os respondentes quanto a outras possibilidades de aplicação dos recursos do Programa Consulta Popular, solicitou-se que os mesmos indicassem que razões, na sua visão, levam a população da região nordeste a priorizar as áreas de saúde, educação e segurança (que já possuem dotações significativas por força legal), deixando de aproveitar a oportunidade de investir em outros projetos estruturantes, que como visto nas páginas pretéritas, também não são contemplados com recursos endógenos como, por exemplo, a agricultura. Dentre as várias respostas, observa-se uma mesma tendência na explicação, coadunando com a de "C3", o qual alega que o "motivo que as dotações existentes nessas áreas são pequenas diante da necessidade da população, por isso necessitase de um reforço". Além destas, encontrou-se outras respostas que merecem ser registradas. Para o "C4" "geralmente há um 'lobby' de representantes das áreas de saúde, educação e segurança, que têm o poder de convencimento da população. Penso que a questão de projetos estruturantes como geração de renda e meio ambiente devam ser trabalhados com as lideranças municipais, além dos COMUDEs, envolvendo também os representantes da saúde, educação e segurança". A resposta do conselheiro "C7" foi a seguinte: "Sim, entendo existir, pois esses outros seriam prioridades para o desenvolvimento sustentável da região, seriam estruturantes, mas para isso haveria talvez a necessidade de maior conscientização através da divulgação da importância". O entrevistado "C9" é mais crítico: "Falta de visão futura. O nosso povo ainda é imediatista e paternalista. A região nordeste só vai crescer quando tiver um plano de desenvolvimento coletivo a médio e longo prazo". Nas respostas dos conselheiros a essa questão, pode-se verificar que todos se preocupam em apoiar projetos em áreas que tragam um maior desenvolvimento à região, porém, na interpretação das respostas, há que se trabalhar a conscientização da população para isso e buscar junto às entidades ligadas às áreas de saúde, educação e segurança, disseminar o conceito mais abrangente de desenvolvimento, uma vez que esses buscam de todas as formas recursos para suas pastas, sem avaliar o verdadeiro foco do programa. Outros pontos levantados nas respostas são a falta de planejamento local e regional, falta de visão futura e gestores descomprometidos com o "regional".

As respostas dos conselheiros aos questionamentos propostos foram de grande importância para esse estudo e pode-se traçar um comparativo com os levantamentos de dados sobre as ações apoiadas pela Consulta Popular nesses anos. Pode-se tirar como conclusão que os conselheiros têm em mente 
a concepção do regional, de programas estruturantes, porém pelas respostas percebe-se que são desviados desses ideais pelos gestores municipais e seus subordinados, que trabalham para que a Consulta Popular se torne uma fonte de recurso para projetos de interesse próprio e local, deixando para o futuro a questão do desenvolvimento regional.

\section{CONSIDERAÇÕES FINAIS}

Após a análise dos dados, pode-se concluir que a região do COREDE NORDESTE, neste programa, prioriza investimentos em áreas que naturalmente possuem repasses constitucionais obrigatórios, deixando de aplicá-los em programas que poderiam propiciar à região um incremento em outras áreas de interesse ao desenvolvimento regional.

Dos valores aplicados nos quatro anos considerados para esta pesquisa, a região investiu recursos na área da saúde $(33,52 \%)$, da agricultura investimentos $(18,73 \%)$, da agricultura geração de renda (15,35\%), da segurança (11,01\%) e de saneamento (10,37\%). No outro extremo, encontram-se as áreas de turismo, pesquisa, ciência e tecnologia, cultura e meio ambiente que não conseguem atingir o montante de $2 \%$ cada um, dos recursos destinados.

No tocante ao desenvolvimento sustentável, pode-se dizer que os recursos estão sendo aplicados com ênfase no desenvolvimento social, deixando em segundo plano o desenvolvimento econômico e o ambiental. Ao se analisar a canalização dos recursos, observa-se que quando há um direcionamento em termos de aplicação dos recursos, por parte das lideranças que coordenam o COREDE NORDESTE, estes são aplicados seguindo o seu direcionamento. Pelas respostas dos conselheiros do COREDE aos questionamentos, verificase que a falta de um planejamento estratégico regional leva a população deste COREDE e seus gestores públicos a focarem necessidades em seus municípios, afastando-se do propósito maior que é o desenvolvimento da região.

Observa-se pela distribuição dos recursos que a prioridade dada pela população leva à utilização desses recursos para solução de problemas municipais. Isso ocorre devido à ação de lideranças, que através de suas redes de poder instigam a população a votar em áreas que auxiliam a operacionalizar suas estratégias/objetivos, fazendo com que os poucos recursos sejam aplicados em áreas já bastante contempladas nos orçamentos anuais dos municípios. É visível, nos argumentos dos consultados, que existe ainda na região estudada uma visão focada em problemas municipais entre a população e gestores públicos, havendo

Novos Cadernos NAEA • v. 17 n. 1 • p. 9-24 • jun. 2014 
necessidade de reverter esse quadro para que se consiga implantar programas de cunho regional.

A razão do investimento priorizando áreas, de um lado, pode ser atribuída a inexistência de um planejamento regional e, de outro, pela capacidade de mobilização dos ocupantes de cargos nessas áreas que buscam recursos para as suas pastas. Não se deve, no entanto, minimizar a necessidade da população, pois transparece nos argumentos dos conselheiros que a área de saúde é uma das que mais necessitam de investimentos.

Antes de finalizar este artigo, há necessidade de reconhecer os limites do estudo aqui proposto. Em se tratando de um estudo de caso único, devese considerar a impossibilidade de generalizar os resultados para os demais conselhos do Estado, visto que cada região possui suas peculiaridades, cultura e visão desenvolvimentista. Nesse caso, fica como sugestão replicar o estudo em outras áreas e verificar se esse resultado se repete. Apesar das limitações, os objetivos propostos foram alcançados, sendo possível concluir que alcançar o objetivo da participação é importante em termos de política pública. Todavia, não garante que os recursos sejam aplicados de maneira coerente pela população. Verifica-se, pelo menos no caso estudado, que quando há um direcionamento por parte dos líderes que fazem parte do conselho ou de lideranças locais, a população se mobiliza para aprovar propostas orientadas por elas. Diante disso, entende-se que o modelo de gestão descentralizada dos recursos ainda carece de ajustes, a fim de alcançarem congruência com a prática.

\section{REFERÊNCIAS}

ALVEZ-MAZZOTI, A. J.; GEWANDSZNAJOER, F. O método nas ciências naturais e sociais: pesquisa quantitativa e qualitativa. São Paulo: Pioneira, 2001.

AMORIM, C. C. Discutindo o conceito de região. Estação Cientifica Online, Juiz de Fora, n. 04, abr./mai. 2007.

ATLAS SOCIOECONÔMICO DO RIO GRANDE DO SUL. Regiões dos

COREDES. 2006. Disponível em: http://www.seplag.rs.gov.br/atlas/atlas. asp?menu=631. Acesso em: 2 set. 2009.

BANDEIRA, P. S. Participação, articulação de atores sociais e desenvolvimento regional. In: BECKER, D. F; BANDEIRA, P. S. Determinantes e desafios contemporâneos. Santa Cruz do Sul: EDUNISC, 2000. 
GIL, A. C. Métodos e técnicas de pesquisa social. São Paulo: Atlas, 2009.

GODOY, A. S. Introdução à pesquisa qualitativa e suas possibilidades. Revista de Administração de Empresas, EAESP / FGV, São Paulo, v. 35, n. 2, p. $57-$ 63, mar./abr. 1995.

HADDAD, P. R. (Org.). Economia Regional: teorias e métodos de análise. Fortaleza: BNB, 1989.

LENCIONI, S. Região e Geografia. São Paulo: EDUSP, 1999.

MARTINELLI, D. P.; JOYAL, A. Desenvolvimento local e o papel das pequenas e médias empresas. Barueri: Manole, 2004.

PAIVA, C. A. N. Regionalização com vistas ao planejamento do desenvolvimento endógeno sustentável. In: PRIMEIRAS JORNADAS DE ECONOMIA COMPARADA, 1, Porto Alegre 2005. Anais... Porto Alegre, FEE/PUCRS. Disponível em: http://www.fee.tche.br/sitefee/download/jornadas/2/e4-07. pdf. Acesso em: 30 jul. 2009.

PARADA, E. L. Introducción a las políticas públicas. Santiago: Fondo de Cultura Económica, 2002.

PASSADOR, C. S. O projeto escola do campo (1990-2002) do estado do Paraná: capital social, redes e agricultura familiar nas políticas públicas. 2003. 176 f. Tese (Doutorado em Educação) - Faculdade de Educação, Universidade de São Paulo, São Paulo, 2003.

SANTOS, M. Cidades na era global. Revista Cidades, São Paulo, 2 (13): 12-14, maio. 1997.

SEN, A. Desenvolvimento como liberdade. São Paulo: Companhia das Letras, 2000 .

SOUZA, M. L. de. Desenvolvimento de comunidade e participação. São Paulo: Cortez, 1999. 